\title{
The Research and Practice of Applied Undergraduate Professional Tutorial System
}

\author{
Xin Zhao ${ }^{1, \text { a }}$, Jing Wang ${ }^{1, b}$ \\ ${ }^{1}$ College of Information Technology, Jilin Agricultural University, Changchun 130118, China; \\ ajlndzx@sina.com, b'wangjing2227@sina.com
}

Keywords: Tutorial system for undergraduates, Innovative applied talent, Individual guidance, Teaching management, Two-way choice

\begin{abstract}
Teaching management is according to the teaching characteristics and rules to manage various aspects of teaching process. As a teaching method, tutorial system for undergraduates combine teaching and education together, adhere to the people-oriented as the center, with emphasis on the individual education. In this thesis, the connotation of tutorial system for undergraduates, characteristics, significance and problems and so on has carried on the detailed narration, and aim at the concrete method and the result of tutorial system for undergraduates trial of Jilin Agricultural University College of information technology is a conducted in-depth research and thinking.
\end{abstract}

\section{Preface}

China's Ministry of Education promulgated the "action plan for the twenty-first Century education revitalization" in 1999 documents mentioned that the higher education gross enrollment rate will reach $15 \%$ of school-age youth in $2010^{[1]}$. As a result, the enrollment scale of our country began to expand in a few years. The entrance pressure relief, but at the same time, with the number of students increased significantly, the heavy burden on the teachers, decline in the quality of teaching, students can not get special guidance, personal ability is not enough, can not be fully developed ${ }^{[2]}$. With the development of the society, we must fully develop themselves. It is in this context, as an effective way of new guidance, tutorial system for undergraduates arises at the historic moment.

\section{The concept of the tutorial system for undergraduates}

Tutorial system for undergraduates is a kind of individual guidance system in universities. Students in the class system as well as the instructor system at the same time, under the premise of two-way selection for different students to arrange different instructors, they are not only responsible for students' learning, scientific research, but also responsible for guiding the student's thought and life.The tutorial system for undergraduates take human as center and combinate teaching and education, carrying out the modern education idea of educating people in all round way ${ }^{[3]}$.

\section{The origin and development of the tutorial system for undergraduates}

England's William Wykeham proposed the tutorial system first in 1379. In late nineteenth Century and early twentieth Century, Harvard University, Yale University, Princeton University and other colleges have begun to implement the tutorial system. The tutorial system for undergraduates was first implemented by Zhejiang University in China ${ }^{[4-5]}$. With the continuous development of society and people's deeper understanding of Education, there are a lot of schools have begun to implement the tutorial system for undergraduates, this system has also been greatly developed in our country.

\section{The characteristics and significance of the tutorial system for undergraduates}

First, the tutorial system for undergraduates is a new teaching system, tutors have more energy, they can teach students learning and life directly and make students better adapt to the next college life. Second, the undergraduate tutor knows more about his students so that they can teach students in 
accordance of students' aptitude and let students exploit their potential to get a better develop. Third, students can get professional guidance learning, undergraduate tutors have more time and energy to help students enhance their autonomous learning ability, train students' experimental ability and thinking ability so that students become the talents with application and innovation ability. Then, it is in line with the requirements of quality education in china, they can combine teaching and nurtures person together to make students develop both study and mind to become a highly quality talent. Finally, tutors can give targted graduation guidance to students, they can base on students' situation to help them choose the direction of employment or entrance exams when graduating, so that students can avoid the confusion after graduation.

\section{The problems of the tutorial system for undergraduates}

In the first place, the expansion of college students caused a serious imbalance between the proportion of teachers and students, the advantage of tutorial system can not get maximum play. Next, tutors' time and energy is limited and students are very ignorant of everything, these lead to the initiative of teachers and students is not enough and lack of enthusiasm. Third, it is difficult to define the relationship and difference between the tutor and the headmaster and the counselor teacher, they are hardly to define what work they are supposed to be responsible. Last, tutors do not know whether their work is perfect and students do not know how their learning situation without reasonable assessment, and there is no appropriate incentive system to improve the enthusiasm of teachers and students ${ }^{[6]}$.

\section{The practice course of our school}

By analysing the problems in the implementation of the tutorial system for undergraduates of other school, Jilin Agricultural University College of information technology has carried on corresponding reform and has carried the tutorial system for undergraduates for grade 2011 students.

\subsection{The selection and the equipment of the tutors and the students}

Let the students and instructors make two-way choice.

(1) determine the appropriate teachers identified as the undergraduate tutors in the first week of the new student enrollment in the college and brought back five retired teacher to ensure that every teacher with no more than two students.

(2) Conduct propaganda meetings in the second week, the list and basic information of tutors will be uploaded to the network at the same time to help students to consult.

(3) All the students report the selection list according to their own interest.

(4) The number of public class teachers should not be more than two students, the number of professional courses teachers with a difference of not more than one person.

(5) Tutors need to choose according to the choice of students. To the end of the second semester.

(6) All the students carry out the second two-way selection at the first week of the third semester, the way is the same to the first time, and continue guide them until graduating.

\subsection{Make the specific system of the tutorial system for undergraduates}

(1) Tutors should pay attention to their behavior in the daily life, pay attention to their personal accomplishment, and they should establish an equal relationship with the students.

(2) Tutors should have a sound working mechanism to tap the inherent potential of students.

(3) Tutors should lead students to participate in mathematical modeling and other research projects so that students can learn to think independently and to exercise the students' experimental ability.

(4) Students should improve their enthusiasm, they need to communicate with the teacher at least two times a week and submit the study summary to their teacher regularly.

(5) Save records and information of students, college will hold a seminar at the end of each term to conduct an appraisal and give small gifts to the victorious instructors and students, these assessments will also serve as part of the scholarship evaluation of each semester. 


\subsection{Analysis of trial results}

In order to directly see whether the implementation of the tutorial system for undergraduates have improved various aspects of students, we calculate average the data from grade 2006 to grade 2010 of graduates as the basic data of the before the implementation of tutorial system, and take the data of grade 2011 as the basic data of the after the implementation of undergraduate tutorial system. We carry out chi-square test on these data from four aspects, and data and test results are shown in Tab.1, Tab.2, Tab.3 and Tab.4.

Table. 1 The compare of the rate of don't pass the exam

\begin{tabular}{ccccc}
\multirow{2}{*}{ Group } & \multicolumn{2}{c}{ Attribute } & \multirow{2}{*}{ Total } & E \\
\cline { 2 - 4 } & C & D & & \\
A & $10(7.54)$ & $79(81.46)$ & 89 & $11.2 \%$ \\
B & $5(7.46)$ & $83(80.54)$ & 88 & $5.6 \%$ \\
\hline Total & 15 & 162 & 177 & $8.5 \%$ \\
\hline
\end{tabular}

A: Before the implementation of tutorial system

B: After the implementation of tutorial system

C: The number of failing the exam

D: The number of through the exam

E: The rate of don't pass the exam

Table.2 The compare of the rate of pass postgraduate entrance examination

\begin{tabular}{|c|c|c|c|c|c|}
\hline \multirow{2}{*}{ Group } & \multicolumn{2}{|c|}{ Attribute } & \multirow{2}{*}{ Total } & \multirow{2}{*}{$\mathrm{H}$} & \multirow{3}{*}{$\begin{array}{l}\text { A: Before the implementation of tutorial system } \\
\text { B: After the implementation of tutorial system } \\
\text { F: The number of pass postgraduate entrance } \\
\text { examination }\end{array}$} \\
\hline & $\mathrm{F}$ & $\mathrm{G}$ & & & \\
\hline A & $6(9.05)$ & $83(79.95)$ & 89 & $6.7 \%$ & \\
\hline B & 12(8.95) & 76(79.05) & 88 & $13.6 \%$ & $\begin{array}{l}\text { G: The number of don't pass postgraduate entrance } \\
\text { examination }\end{array}$ \\
\hline Total & 18 & 159 & 177 & $10.2 \%$ & $\begin{array}{l}\mathrm{H}: \text { The rate of pass postgraduate entrance } \\
\text { examination }\end{array}$ \\
\hline
\end{tabular}

Table.3 The compare of the employment rate

\begin{tabular}{ccccc}
\multirow{2}{*}{ Group } & \multicolumn{2}{c}{ Attribute } & \multirow{2}{*}{ Total } & K \\
\cline { 2 - 3 } & I & J & & \\
\hline A & $82(82.97)$ & $7(6.03)$ & 89 & $92.1 \%$ \\
B & $83(82.03)$ & $5(5.97)$ & 88 & $94.3 \%$ \\
\hline Total & 165 & 12 & 177 & $93.2 \%$
\end{tabular}

A: Before the implementation of tutorial system B: After the implementation of tutorial system I: The number of people working $\mathrm{J}$ : The number of people don't working $\mathrm{K}$ : The employment rate

Table.4 The compare of the rate of demotion

\begin{tabular}{ccccc}
\multirow{2}{*}{ Group } & \multicolumn{2}{c}{ Attribute } & Total & $\mathrm{N}$ \\
\cline { 2 - 3 } & $\mathrm{L}$ & $\mathrm{M}$ & & \\
\hline $\mathrm{A}$ & $2(1.51)$ & $87(87.49)$ & 89 & $2.2 \%$ \\
$\mathrm{~B}$ & $1(1.49)$ & $87(86.51)$ & 88 & $1.1 \%$ \\
\hline Total & 3 & 174 & 177 & $1.7 \%$
\end{tabular}

A: Before the implementation of tutorial system

$\mathrm{B}$ : After the implementation of tutorial system

L: The number of people demote

M: The number of people don't demote $\mathrm{N}$ : The rate of demotion

The result of the chi-square test shows that $<0.1,<0.1,<0.1,<0.1$, so the implementation of the tutorial system for undergraduates has a significant impact on these four aspects.

\subsection{Summary}

After the College of information technology of Jilin Agricultural University implement the tutorial system for undergraduates, the employment rate and the rate of pass postgraduate entrance examination have improved Significantly, the rate of don't pass the exam and the rate of demotion has been reduced to a certain extent. Overall, it can be said that the implemention of the tutorial system for undergraduates, truly realize the common progress of the students and teachers.

\section{Conclusion}

Through the study and analysis, we know that the tutorial system for undergraduates is a new management mode of application oriented undergraduate with good prospects for promotion and improvement. Students can understand their own potential more deeply, students will have more 
opportunity to link theory with practice, so as to develop students into a real sense of innovative applied talent. At the same time, teachers can improve the teaching methods to raise their level of job, find a more in-depth teaching breakthrough point, and make progress together with students. But the tutorial system for undergraduates in the implementation of the process will have different problems in different school, by analyzing the whole process, the system design and the result of the undergraduate tutorial system in Jilin Agricultural University. We understand that we must combine the undergraduate tutor system with characteristics of the universities to get twice the result with half the effort. Learning is endless, the perfection of the tutorial system for undergraduates has no end, we will with the development of the eye, the rigorous attitude, down-to-earth to promote and explore undergraduate tutor system.

\section{Acknowledgments}

This work is supported financially by Excellent teaching team project of Jilin Agricultural University. The correspondence author is Jing Wang, wangjing2227@sina.com.

\section{References}

[1]Jing Guo-an. The advisor institution of the undergraduate: an educational innovation in university[J]. Journal of Higher Education, 2005, (5): 80-84.

[2]Ji Xiao-yi. Praetice on and research the student - managing model of the college tutorial systemWenzhou University as an example[D]. East China Normal University, 2006.

[3]Chen Guo-ping, Wang Xiao-fei, Yu Feng-yuan. A study on tutorial system for the cultivation of undergraduates of applied majors-from the perspective of its necessity and feasibility[J]. Journal of Huangshan University, 2012, 40(6): 86-90.

[4] Wu Li-shuang. Exploring and analysis on the diversified tutorial system of undergraduate students in local colleges and universities[J]. China Higher Education Research, 2014, (5): 74-76.

[5]Yu Shi-ming, Zhao Wei. Theory and practice of undergraduate tutorial system[J]. Journal of Shenyang Normal University (Social Science Edition), 2011, 35(1): 120-122.

[6]Wang Jian-fang, Wu Wen-jian, Man Ya-hui. A preliminary study on the teaching reform of undergraduate tutorial system [J]. Journal of Higher Education research, 2006, 29(1): 44-46. 